\title{
Cross-Resistance of UV- or Chlorine Dioxide-Resistant Echovirus 11 to Other Disinfectants
}

\author{
Qingxia Zhong, Anna Carratalà, Rachele Ossola ${ }^{\dagger}$, Virginie Bachmann and Tamar Kohn* \\ Laboratory of Environmental Chemistry, School of Architecture, Civil and Environmental Engineering, École Polytechnique \\ Fédérale de Lausanne, Lausanne, Switzerland
}

OPEN ACCESS

Edited by:

Muhammad Raihan Jumat,

King Abdullah University of Science

and Technology, Saudi Arabia

Reviewed by:

Thanh Nguyen,

University of Illinois at

Urbana-Champaign, United States

Xavier Abad,

Centre de Recerca en Sanitat Animal,

Spain

*Correspondence:

Tamar Kohn

tamar.kohn@epfl.ch

${ }^{\dagger}$ Present Address:

Rachele Ossola,

Environmental Chemistry Group,

Department of Environmental Systems

Science, Swiss Federal Institute of

Technology in Zurich (ETH), Zurich,

Switzerland

Specialty section:

This article was submitted to Microbiotechnology, Ecotoxicology and Bioremediation,

a section of the journal

Frontiers in Microbiology

Received: 28 July 2017 Accepted: 21 September 2017

Published: 04 October 2017

Citation:

Zhong Q, Carratalà A, Ossola R, Bachmann V and Kohn T (2017) Cross-Resistance of UV- or Chlorine Dioxide-Resistant Echovirus 11 to Other Disinfectants.

Front. Microbiol. 8:1928.

doi: 10.3389/fmicb.2017.01928
The emergence of waterborne viruses with resistance to disinfection has been demonstrated in the laboratory and in the environment. Yet, the implications of such resistance for virus control remain obscure. In this study we investigate if viruses with resistance to a given disinfection method exhibit cross-resistance to other disinfectants. Chlorine dioxide $\left(\mathrm{ClO}_{2}\right)$ - or UV-resistant populations of echovirus 11 were exposed to five inactivating treatments (free chlorine, $\mathrm{ClO}_{2}$, UV radiation, sunlight, and heat), and the extent of cross-resistance was determined. The $\mathrm{ClO}_{2}$-resistant population exhibited cross-resistance to free chlorine, but to none of the other inactivating treatments tested. We furthermore demonstrated that $\mathrm{ClO}_{2}$ and free chlorine act by a similar mechanism, in that they mainly inhibit the binding of echovirus 11 to its host cell. As such, viruses with host binding mechanisms that can withstand $\mathrm{ClO}_{2}$ treatment were also better able to withstand oxidation by free chlorine. Conversely, the UV-resistant population was not significantly cross-resistant to any other disinfection treatment. Overall, our results indicate that viruses with resistance to multiple disinfectants exist, but that they can be controlled by inactivating methods that operate by a distinctly different mechanism. We therefore suggest to utilize two disinfection barriers that act by different mechanisms in order to control disinfection-resistant viruses.

Keywords: environmental virology, virus disinfection, echovirus 11, cross-resistance, water treatment

\section{INTRODUCTION}

Waterborne and foodborne viruses are typically efficiently controlled by chemical (e.g., free chlorine and ozone) or physical [e.g., ultraviolet (UV) radiation] disinfectants. However, it is welldocumented that viruses may evolve to exhibit tolerance to disinfection. For example, poliovirus isolated from chlorinated drinking water was found to be chlorine-resistant (Shaffer et al., 1980). Similarly, isolates of coxsackievirus B5 from sewage or tap water were more resistant to chlorination compared to their corresponding lab strain (Payment et al., 1985). Finally, resistant viruses can also readily be generated in the laboratory by experimental evolution (Bates et al., 1977; Maillard et al., 1998; Zhong et al., 2016).

While the occurrence of disinfection resistance among virus populations has thus been established, information is lacking regarding the prevalence of such resistant viruses in water distribution system and the environment, or about their overall fitness and contribution to waterborne infections. Given the challenges associated with isolating and identifying such viruses, it is currently unlikely that such information will be routinely obtained in the near future. As such, 
it appears advisable to design treatment strategies that can control disinfection-resistant viruses, to avoid their proliferation in the first place.

To inactivate a virus, a disinfectant must inhibit one or more of its vital functions, which include host binding, host entry and genome replication. Different disinfectants can target different viral functions. For example, the inactivation of MS2 bacteriophage by $\mathrm{UV}$ at $254 \mathrm{~nm}\left(\mathrm{UV}_{254}\right)$ is mainly driven by genome damage, which results in the inability of the virus to successfully replicate (Wigginton et al., 2012). In contrast, MS2 inactivation by chlorine dioxide $\left(\mathrm{ClO}_{2}\right)$ is dominated by damage to the protein capsid, leading to the inability of the virus to bind to its host (Wigginton et al., 2012). A possible treatment strategy for viruses with resistance to a given disinfectant may therefore be the application of a disinfectant with a different mode of action (Ballester and Malley, 2004). This approach, however, can only work if a virus does not exhibit cross-resistance to other inactivation mechanisms.

In this work we determined if $\mathrm{UV}_{254}$ - or $\mathrm{ClO}_{2}$-resistant strains of the echovirus 11 (E11) can be controlled by inactivating agents with a different mode of action. Echoviruses are enteric pathogens with clinical manifestations ranging from mild symptoms to more severe diseases such as meningitis, encephalitis, myocarditis, and hemorrhagic conjunctivitis (Knipe and Howley, 2007). They are members of the Enterovirus genus, which is frequently detected in the aqueous environment (Fong and Lipp, 2005 and references therein). Due to Enterovirus' potential risk to public health via contaminated water (Ford, 1999), this genus was included in the USEPA's Drinking Water Contaminant Candidate List (CCL) (USEPA, 2016). Here, we investigated the susceptibility of resistant E11 populations to treatments commonly applied to control pathogens in water, wastewater and food [free chlorine (FC), $\mathrm{ClO}_{2}, \mathrm{UV}_{254}$, and heat], as well as to an important environmental stressor, namely sunlight.

The action of several disinfectants on members of the Enterovirus genus have been previously investigated, yet the dominant inactivation mechanisms remain debated. Different experimental conditions used in different studies with respect to disinfectant concentration, contact time, temperature, $\mathrm{pH}$, or ionic strength, further complicate a comparison of the different findings. For example, Nuanualsuwan and Cliver (2003b) suggested that the poliovirus genome is the primary target of FC inactivation, though in another study conducted at a lower FC working concentration, they observed binding loss for poliovirus and hepatitis A virus (Nuanualsuwan and Cliver, 2003a). Similarly, these researchers reported the genome to be the major target during poliovirus inactivation by $\mathrm{UV}_{254}$ (Nuanualsuwan and Cliver, 2003b), though in a different study they also observed binding loss (Nuanualsuwan and Cliver, 2003a). For $\mathrm{ClO}_{2}$, the discrepancy in experimental conditions used in different studies also led to a lack of consensus regarding its mode of action. Olivieri et al. (1985) demonstrated that the genomes of inactivated poliovirus were still infectious, thus suggesting that the genome was not the main target of $\mathrm{ClO}_{2}$. In contrast, Simonet and Gantzer (2006), who worked with high $\mathrm{ClO}_{2}$ exposures (5 $\mathrm{mg} / \mathrm{L}$ during $120 \mathrm{~min}$ ), reported that viral
RNA did degrade, but did not fully account for inactivation. Genome damage, specifically damage to the $5^{\prime}$ non-coding region, was found to be the main target for the treatment of enterovirus 71 and Hepatitis $\mathrm{A}$ virus at $\mathrm{ClO}_{2}$ exposures of 13.5 mg/L*min or higher (Li et al., 2004; Jin et al., 2013). These authors also reported a similar finding for the inactivation of poliovirus by lower $\mathrm{ClO}_{2}$ exposures (0.1-1.2 $\mathrm{mg} / \mathrm{L}$ during 1-12 min) (Jin et al., 2012). Similarly, an additional study of poliovirus by $\mathrm{ClO}_{2}$ at a low $\mathrm{ClO}_{2}$ exposure $(1 \mathrm{mg} / \mathrm{L}$ for $2 \mathrm{~min}$ ) concluded that a loss in genome replicability was the main mode of $\mathrm{ClO}_{2}$ action, whereas loss in host binding was ruled out (Alvarez and O'Brien, 1982). In contrast, our previous work on inactivation of E11 at similarly low $\mathrm{ClO}_{2}$ exposures (up to $1.5 \mathrm{mg} / \mathrm{L}^{*} \mathrm{~min}$ ) revealed that inactivation coincided with a decrease in host binding, though the loss in this function did not fully account for inactivation (Zhong et al., 2017). Combined, these studies highlight that a comprehensive understanding of the mechanisms of action of these disinfectants, and their dependence on the experimental conditions, is thus still lacking.

Here, we determined the kinetics of inactivation of $\mathrm{ClO}_{2}$ - or $\mathrm{UV}_{254}$-resistant $\mathrm{E} 11$ populations by $\mathrm{ClO}_{2}, \mathrm{FC}$, heat, $\mathrm{UV}_{254}$, and sunlight, and compared them to the inactivation kinetics of the corresponding wild-type E11. This allowed us to determine the occurrence and extent of cross-resistance among the disinfection methods tested. We then investigated the main inactivation mechanisms acting on E11 during treatment by these disinfection methods, to evaluate if cross-resistance only affected disinfectants acting by a similar mechanism, or if resistance was a general trait. Finally, we interpreted the results in the context of possible implications for the control of resistant viruses.

\section{EXPERIMENTAL SECTION}

\section{Cells and Viruses}

BGMK cells, Escherichia coli, E11 and bacteriophage MS2 were cultured and maintained as described previously (Zhong et al., 2016, 2017). Infective E11 concentrations were enumerated as most probable number of cytopathic units per $\mathrm{mL}(\mathrm{MPNCU} / \mathrm{mL})$, and infective MS2 concentrations were determined as plaque forming units per $\mathrm{mL}(\mathrm{PFU} / \mathrm{mL})$ (Suess, 1982).

\section{Resistant Echovirus and Their Corresponding Wild-Types}

$\mathrm{ClO}_{2}$-resistant and $\mathrm{UV}_{254}$-resistant $\mathrm{E} 11$ populations were obtained by experimental evolution (Figure 1). The production of $\mathrm{ClO}_{2}$-resistant populations was described in detail in Zhong et al. (2017). Briefly, the E11 laboratory strain, here denoted as "wild-type" (WT), was subjected to 20 passages of directed evolution. During each passage, the virus population was exposed to $\mathrm{ClO}_{2}$ up to an exposure of $6 \mathrm{mg} / \mathrm{L}^{*} \mathrm{~min}$, resulting in an inactivation of at least $3 \log _{10}$, before the inactivation was halted and the remaining virus population was regrown on BGMK cells. The resulting $\mathrm{ClO}_{2}$-resistant population is henceforth referred to as $\mathrm{E} \_\mathrm{ClO}_{2}$ ("exposed to $\mathrm{ClO}_{2}$ "). A similar approach was used to obtain $\mathrm{UV}_{254}$-resistant E11, except that a different ancestral population of E11 was used. Specifically, prior to any 


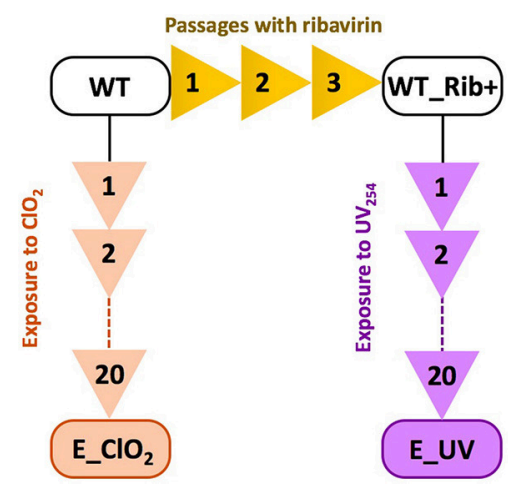

FIGURE 1 | Overview over the experimental evolution lineages to produce resistant populations $\mathrm{E}_{-} \mathrm{ClO}_{2}$ and E_UV from their wild-types WT or WT Rib+.

exposure to $\mathrm{UV}_{254}$, the E11 lab strain (WT) was first subjected to three cell culture adaptation passages in the presence of the mutagen ribavirin (Fluorochem), to enhance the genetic diversity of the starting population (Crotty et al., 2000). This population (WT_Rib+) was then subjected to 20 passages of titer reduction by $\mathrm{UV}_{254}$ followed by regrowth. The details of the $\mathrm{UV}_{254}$ setup are given in the following section. The resulting $\mathrm{UV}_{254}$-resistant population is named E_UV hereafter. Both evolved populations at their last (20th) passage as well as the corresponding wildtypes were sequenced as described below and the mutations of the evolved populations are listed in Table $\mathbf{1}$.

\section{Cross-Resistance Experiments}

All inactivation experiments were performed in phosphatebuffered saline [PBS; $5 \mathrm{mM} \mathrm{Na} \mathrm{HPO}_{4}$ (99\%, Acros), $10 \mathrm{mM}$ $\mathrm{NaCl}$ (99.5\%, Acros), pH 7.4], at a starting E11 concentration of $10^{6}-10^{7} \mathrm{MPNCU} / \mathrm{mL}$. The specific inactivation assays associated with the different methods tested are summarized below. Kinetic analyses were performed by monitoring the loss of infective E11 as a function of disinfectant exposure (oxidants), dose ( $\mathrm{UV}_{254}$ and solar radiation), or time (heat).

\section{Chlorine Dioxide $\left(\mathrm{ClO}_{2}\right)$}

Concentrated $\mathrm{ClO}_{2}$ was produced as described previously (Zhong et al., 2016) and stored in the refrigerator at $4^{\circ} \mathrm{C}$. Working solutions were prepared in PBS immediately prior to the experiment.

Inactivation by $\mathrm{ClO}_{2}$ was conducted in continuously stirred $10 \mathrm{~mL}$ beakers on ice containing $2 \mathrm{~mL}$ of PBS and an initial $\mathrm{ClO}_{2}$ concentration of $1 \mathrm{mg} / \mathrm{L}$. Samples were withdrawn periodically at time intervals of $10 \mathrm{~s}$ to $1 \mathrm{~min}$ over the course of up to $5 \mathrm{~min}$, were mixed with sodium thiosulfate (98\%, SigmaAldrich) to quench the residual $\mathrm{ClO}_{2}$, and the virus titer $(N)$ was enumerated. Control experiments showed that the addition of sodium thiosulfate did not affect virus infectivity, viral functions, or genome extraction in the subsequent experimental procedures. The $\mathrm{ClO}_{2}$ concentration was monitored at the beginning $\left(C_{\mathrm{ClO}, 0}\right)$ and periodically throughout the experiment $\left(C_{\mathrm{ClO} 2}\right)$ using the chlorophenol red (Sigma-Aldrich) method described by Fletcher and Hemmings (1985). The $\mathrm{ClO}_{2}$ decay
TABLE 1 | Heat map of the frequency of alleles that changed from minor to major or from major to fixed in the evolved populations $\mathrm{E}_{-} \mathrm{ClO}_{2}$ and $\mathrm{E} \_$UV.

\begin{tabular}{|c|c|c|c|c|}
\hline \multicolumn{3}{|c|}{10} & \multicolumn{2}{|l|}{100} \\
\hline & NT & AA & E_ClO 2 & E_UV \\
\hline VP4 & A849Ta & Y33F & 0 & 100 \\
\hline \multirow[t]{4}{*}{ VP2 } & $\mathrm{G} 1373 \mathrm{C}^{\mathrm{C}}$ & G139R & 100 & 100 \\
\hline & $\mathrm{A} 2835 \mathrm{G}^{\mathrm{b}}$ & K126R & 61 & 0 \\
\hline & $C 2844 A^{a, d}$ & P129Q & 63 & 100 \\
\hline & T2849A & S131N & 60 & 0 \\
\hline \multirow[t]{4}{*}{ VP1 } & C2850A & S131N & 60 & 0 \\
\hline & C3162T & T235I & 63 & 0 \\
\hline & $A 3170 G^{b}$ & M238V & 63 & 100 \\
\hline & $\mathrm{A} 3233 \mathrm{G}^{\mathrm{b}}$ & K239E & 63 & 99 \\
\hline $2 \mathrm{C}$ & T4200C & V40A & 0 & 100 \\
\hline \multirow[t]{2}{*}{$3 D$} & $\mathrm{~T}_{6006 C^{d}}$ & M19T & 98 & 100 \\
\hline & A6989G & T347A & 1 & 99 \\
\hline
\end{tabular}

Only non-synonymous mutations are included. The location of the mutation, and the resulting change in nucleotide (NT) and amino acid (AA) are listed. Mutations that reached fixation ( $\geq 99 \%)$ are indicated by bold fonts. Shared major alleles among $\mathrm{E}_{-} \mathrm{ClO}_{2}$ and E_UV are shaded in gray.

a These mutations caused an amino acid substitution from $\mathrm{ClO}_{2}$-reactive to stable ones;

${ }^{b}$ These mutations caused an amino acid substitution from FC-reactive to less reactive ones;

${ }^{c}$ At this position, the ancestral WT of $E_{-} \mathrm{ClO}_{2}$ already has a cytosine as a major allele while its frequency increased by more than $30 \%$ in $\mathrm{E}_{-} \mathrm{ClO}_{2}$. Virus WT_Rib+ has a guanosine.

${ }^{d}$ At these positions, the mutations were already fixed in the ancestral WT Rib + of E UV.

throughout the experiment was first order, and the associated decay rate constant $k_{d}\left(\mathrm{~min}^{-1}\right)$ was determined as:

$$
\ln \left(\frac{C_{\mathrm{ClO} 2}}{C_{\mathrm{ClO} 2,0}}\right)=-k_{d} t
$$

The $\mathrm{ClO}_{2}$ exposure at any time point during the inactivation experiment was estimated from the cumulative area under the curve of $\mathrm{C}_{\mathrm{ClO} 2}$ vs. $t$ :

$$
\mathrm{ClO}_{2} \text { exposure }=\int_{0}^{t} \mathrm{C}_{\mathrm{ClO} 2} d t
$$

Kinetic inactivation parameters were obtained by fitting the data to the modified Hom model (Haas and Joffe, 1994):

$$
\ln \frac{N}{N_{0}}=-k_{\mathrm{ClO} 2} C_{\mathrm{ClO} 2,0}^{n} t^{m}\left(\frac{1-\exp \left(-\frac{k_{d} t}{m}\right)}{\frac{k_{d} t}{m}}\right)^{m}
$$

Here $N_{0}$ and $N$ are the virus titers at times 0 and $t$, respectively, and $k_{\mathrm{ClO} 2}$ is the Hom inactivation rate constant $\left[\mathrm{mg}^{-\mathrm{n}} \mathrm{L}^{\mathrm{n}} \min ^{-\mathrm{m}}\right]$. Model parameters $m$ and $n$ were treated as constant across all experiments (Zhong et al., 2016) and corresponded to 0.30 and 0.46 respectively. 


\section{Free Chlorine (FC)}

Inactivation experiments by $\mathrm{FC}$ were conducted analogously to $\mathrm{ClO}_{2}$ experiments. The initial $\mathrm{FC}$ concentrations ranged from 1 to $2 \mathrm{mg} / \mathrm{L}$, and were prepared by diluting $\mathrm{NaClO}$ (13-14\%, Reactorlab SA) in PBS ( $\mathrm{pH}$ 7.4). Samples were taken periodically at time intervals of 10 or $15 \mathrm{~s}$ over the course of up to $90 \mathrm{~s}$. The FC concentration $\left(C_{F C}\right)$ was measured in every sample using the $\mathrm{N}, \mathrm{N}$-diethyl-p-phenylenediamine (Sigma-Aldrich) colorimetric method (Rice et al., 2012). The chlorine exposure was determined from the cumulative area under the curve of $C_{F C}$ vs. $t$ :

$$
\text { FC exposure }=\int_{0}^{t} C_{F C} d t
$$

The inactivation rate constant $k_{F C}$ was then determined using a first-order Chick-Watson model:

$$
\ln \left(\frac{N}{N_{0}}\right)=-k_{F C} \int_{0}^{t} C_{F C} d t
$$

\section{Ultraviolet Radiation $\left(\mathrm{UV}_{\mathbf{2 5 4}}\right)$}

Continuously stirred $10 \mathrm{~mL}$ beakers containing $2 \mathrm{~mL}$ PBS (solution depth: $0.6 \mathrm{~cm}$ ) were spiked with E11 and were placed under a low-pressure $18 \mathrm{~W}$ UV-C lamp (TUV T8 Philips) emitting light at $253.7 \mathrm{~nm}$. All solutions were optically dilute, such that the transmission of $\mathrm{UV}_{254}$ throughout the reactor was $>95 \%$. The fluence rate $\left(I_{U V}\right)$ was determined by actinometry using a solution of iodide (Alfa Aesar) and iodate (Acros) in borate buffer (Acros) (Rahn, 1997), and corresponded to 1.7 $\mathrm{W} / \mathrm{m}^{2}$. The $\mathrm{UV}_{254}$ dose was determined from the product of the fluence rate and time $\left(I_{U V}{ }^{*} t\right)$. Samples $(100 \mu \mathrm{L})$ were taken at $1 \mathrm{~min}$ intervals over the course of $7 \mathrm{~min}$, and BGMK cells were immediately infected in order to enumerate the concentration of infective E11. The $\mathrm{UV}_{254}$ inactivation rate constants $\left(k_{U V}\right)$ were determined from model fits of the data to a first-order Chick-Watson model:

$$
\ln \left(\frac{N}{N_{0}}\right)=-k_{U V} I_{U V} t
$$

\section{Sunlight}

Inactivation experiments with sunlight were performed as described elsewhere (Bosshard et al., 2013). In brief, reactors containing $2 \mathrm{~mL}$ virus solutions at $5 \times 10^{4}--1 \times 10^{6}$ $\mathrm{MPNCU} / \mathrm{mL}$ were placed under a solar simulator (Sun 2000, ABET Technologies) equipped with a $1,000 \mathrm{~W}$ Xenon lamp, an Air mass 1.5 filter, and an atmospheric edge filter. All solutions were optically dilute. The inactivation experiments were conducted in a thermostatic bath at $20^{\circ} \mathrm{C}$ with magnetic bars constantly stirring the reactors. Samples were taken periodically at time intervals of $1-3 \mathrm{~h}$ over the course of $24 \mathrm{~h}$. The solar fluence rate $\left(I_{\text {sun }}\right)$ was determined by a radiometer (ILT900-R, International Light) over the range of 290-315 nm and the inactivation rate constant $k_{\text {sun }}$ was obtained by fitting the data to a first-order Chick-Watson model:

$$
\ln \left(\frac{N}{N_{0}}\right)=-k_{\text {sun }} I_{\text {sun }} t
$$

\section{Heat}

Tolerance to heat was assessed by comparing the decay temperatures of the different E11 populations. Experiments were performed by thermal shift using a PCR thermal cycler (PCR System 9700, GeneAmp). PCR tubes $(250 \mu \mathrm{L})$ each containing 90 $\mu \mathrm{L}$ of PBS were prepared. Ten microliters of virus solution were injected to the first tube, and this tube was immediately cultured to quantify the starting titer of E11. Starting from $38^{\circ} \mathrm{C}$, each thermal shift was set to a $2^{\circ}$ increase in temperature. At each shift, one tube containing PBS was preheated in the thermal cycler for $2 \mathrm{~min}$ before $10 \mu \mathrm{L}$ virus solution were injected into the tube. The solution was then kept at this temperature for $1 \mathrm{~min}$ and thereafter immediately put on ice until enumeration. Segmental linear regression was applied to determine the decay temperature $T d$, at which the infective virus concentration started to decline at a rate that corresponded to the slope of the second segment $(S)$ :

$$
\left\{\begin{array}{l}
\ln \left(\frac{N}{N_{0}}\right)=0, \text { if } T<T d \\
\ln \left(\frac{N}{N_{0}}\right)=-S(T-T d), \text { if } T \geq T d
\end{array}\right.
$$

\section{Identification of Virus Functions Inhibited by Disinfectants}

In order to identify the main viral functions affected during inactivation, we quantified the effect of the different disinfectants on genome replication and on host binding. To this end, E11 WT was inactivated by several orders of magnitude by $\mathrm{ClO}_{2}$, $\mathrm{FC}$, heat, $\mathrm{UV}_{254}$, or sunlight. Isothermal conditions were applied for heat inactivation where viruses were incubated at $56^{\circ} \mathrm{C}$ in a water bath for $5 \mathrm{~min}$. Samples were collected and divided into two aliquots. The first aliquot was diluted and infectious units of the sample were determined by infectivity assay. The other aliquot was subjected to the genome replication or host binding assays described below.

\section{Genome Replication}

The ability of a genome to replicate after inactivation was examined by quantitative reverse transcription-PCR (qRTPCR). Viral RNA was extracted from initial and inactivated samples as described previously (Pecson et al., 2009). Prior to extraction, $\sim 10^{7} \mathrm{PFU} / \mathrm{mL}$ MS2 was added to each sample as an internal reference to correct for differences in the genome extraction efficiency between the initial and inactivated samples. In each viral extract, the copy numbers of four E11 genome segments of approximate 550-base length each (549-1,080, $2,685-3,254,4,227-4,793,5,854-6,364$, using primer sets $3 \mathrm{~F} / 4 \mathrm{R}, 11 \mathrm{~F} / 12 \mathrm{R}, 17 \mathrm{~F} / 18 \mathrm{R}$, and $23 \mathrm{~F} / 24 \mathrm{R}$ as specified previously by Zhong et al., 2017) were quantified. Combined, these segments covered $\sim 30 \%$ of the E11 genome. In addition, the number of MS2 genome copies in each sample was determined using primer set 5'-CCGCTACCTTGCCCTAAAC- $3^{\prime}$ and $5^{\prime}$-GACGACAACCATGCCAAAC- $3^{\prime}$ as described previously (Pecson et al., 2009). The extraction efficiency in each sample was calculated as:

$$
\text { efficiency }=\frac{g \_M S 2}{g \_M S 2_{0}}
$$


where $g_{-} M S 2$ and $g_{-} M S 2_{0}$ are the MS2 genome copy number in the inactivated and the initial samples, respectively. The extraction efficiency in each sample was used to correct the corresponding copy numbers of the different E11 segments. Finally, the intact, PCR-replicable proportion of each E11 genome segment $i$ after disinfection, $\left(\frac{g_{i}}{g_{i}}\right)$, was determined, and was used to estimate the loss in PCR replicability of the whole E11 genome, $\left(\frac{G}{G_{0}}\right)$ using the following extrapolation (Wigginton et al., 2012):

$$
\log \left(\frac{G}{G_{0}}\right)=\log \left[\left(\prod \frac{g_{i}}{g_{i 0}}\right)^{\frac{\text { whole genome length }}{\text { total length of all PCR segments }}}\right]
$$

Further information pertaining to genome extraction and qRTPCR quality control can be found in the Supplementary Material.

\section{Host Binding}

Initial and inactivated (by $\sim 5 \log _{10}$ ) samples were subjected to two binding assays as described in detail elsewhere (Zhong et al., 2017). First, flow cytometry was used to quantify the proportion of BGMK cells with bound viruses before and after inactivation according to a method modified from literature (Triantafilou et al., 2001). This method provided a rapid identification of the disinfecting methods that caused a loss in host binding. Briefly, BGMK cells were harvested and fixed in fixing buffer (4\% paraformaldehyde, Alfa Aesar). Cells were then incubated in blocking buffer (PBS with 1\% bovine serum albumin, SigmaAldrich) for $30 \mathrm{~min}$ before virus samples were added and incubated for $1 \mathrm{~h}$ at room temperature. After incubation, the solution with unbound viruses was discarded and cells were then sequentially incubated with anti-E11 primary antibody (LSBio) and secondary antibody conjugated with FITC (Sigma-Aldrich) on a rotator. Staining was measured using a CyFlow ${ }^{\circledR}$ SL flow cytometer (Partec) and the proportion of cells with viruses bound was analyzed by counting cells with green fluorescence emitted by FITC using FlowMax.

This flow cytometry assay offers a straight-forward method to track host cells with bound viral capsids. However, the method is less suited for direct quantification of bound viruses, and it cannot distinguish between intact virions and empty viral capsids. Therefore, the flow cytometry results were confirmed and refined by directly quantifying the number of viruses bound to cells before and after disinfection by qRT-PCR. In contrast to the flow cytometry assay, this approach targets the viral genome. Briefly, virus samples were inoculated onto BGMK cell monolayers on ice. After $40 \mathrm{~min}$, any unbound viruses were removed by washing with PBS. The cell monolayer was then subjected to three freeze-thaw cycles and subjected to chloroform treatment. Bound viruses $\left(N_{b}\right)$ were harvested and quantified by qRT-PCR as described previously (Zhong et al., 2017) and as further detailed in the Supplementary Material. The difference in qRT-PCR signal between untreated and inactivated virus samples results from a reduction in bound virus, plus the decrease in genome integrity of the targeted segment due to exposure to disinfectants (Wigginton et al., 2012). Hence, the observed binding loss was corrected for the genome decay due to disinfectant exposure. Heat-treated viruses served as a control to assess the extent of non-specific binding of inactivated viruses.

\section{Genome Sequencing}

The genomes of virus populations of interest were extracted, and sequencing libraries were prepared as described previously (Zhong et al., 2017). The whole genomes were then sequenced by Next Generation Sequencing (NGS) at the Lausanne Genomics Technologies Core Facility. Briefly, 300 bp PCR amplicons were purified and pooled to obtain $100 \mathrm{ng}$ of nucleic acids per sample. Libraries of $100 \mathrm{bp}$ double-stranded cDNA were constructed using the TruSeq Stranded mRNA Library Prep kit (Illumina). The library nucleic acid concentrations were measured by Nanodrop 2000 (Thermal Fisher Scientific Inc.) and the cDNA quality was checked by Fragment AnalyzerTM (Advanced Analytical). An Illumina HiSeq 2500 platform was used to sequence up to 6 independent, barcoded and pooled libraries. Reads of 100 nucleotides were trimmed and cleaned for further bioinformatics analysis. Only the genomic positions for which the number of reads exceeded 100 were included in downstream analysis. Single-end reads were aligned to E11 Gregory strain using HTS station (David et al., 2014) to call the nucleotide/base at each position The sequence of WT was used as reference to identify the fixed mutations in all evolved populations.

\section{Statistical Analyses}

To determine if the evolved (E_ClO $\mathrm{Cl}_{2}$ and E_UV) populations were more resistant than their corresponding wild-types, their inactivation rate constants were compared first by paired $t$-test analysis. The comparison of $\mathrm{ClO}_{2}$ inactivation kinetics was done by Likelihood Ratio (LR) test (Haas et al., 2014), where the test statistics were determined by Chi-squared distribution table. For all tests the threshold $p$-value for statistical significance was 0.05 . The goodness-of-fit was evaluated based on the coefficient of determination $\left(R^{2}\right)$, which was determined by GraphPad Prism (Version 6.01, 2012). Unpaired $t$-test or regular one-way ANOVA was applied to compare all other parameters between populations or treatments.

\section{RESULTS}

\section{Inactivation of E11 WT by Different Treatments}

Example inactivation curves of E11 WT by $\mathrm{ClO}_{2}, \mathrm{FC}, \mathrm{UV}_{254}$, sunlight, and heat are shown in Figure 2. The inactivation of E11 WT by to FC, $\mathrm{UV}_{254}$, and sunlight were first-order with respect to the disinfectant exposure over the inactivation range tested. The inactivation curve of $\mathrm{ClO}_{2}$, in contrast, tailed off at higher $\mathrm{ClO}_{2}$ exposures. Despite this tail, a $3 \log _{10}(99.9 \%$; $6.9 \ln )$ reduction in the infective viral load could be readily achieved (within minutes) by $\mathrm{ClO}_{2}$ at the disinfectant exposures tested. Inactivation by $\mathrm{FC}$ and $\mathrm{UV}_{254}$ at the conditions employed herein were similarly effective. In contrast, inactivation by simulated sunlight proceeded more slowly, such that a $3 \log _{10}$ inactivation required several hours of exposure. Finally, inactivation by thermal shift revealed that the decay temperature of E11 was around $41^{\circ} \mathrm{C}$. Beyond this temperature, $3 \log _{10}$ virus decay 

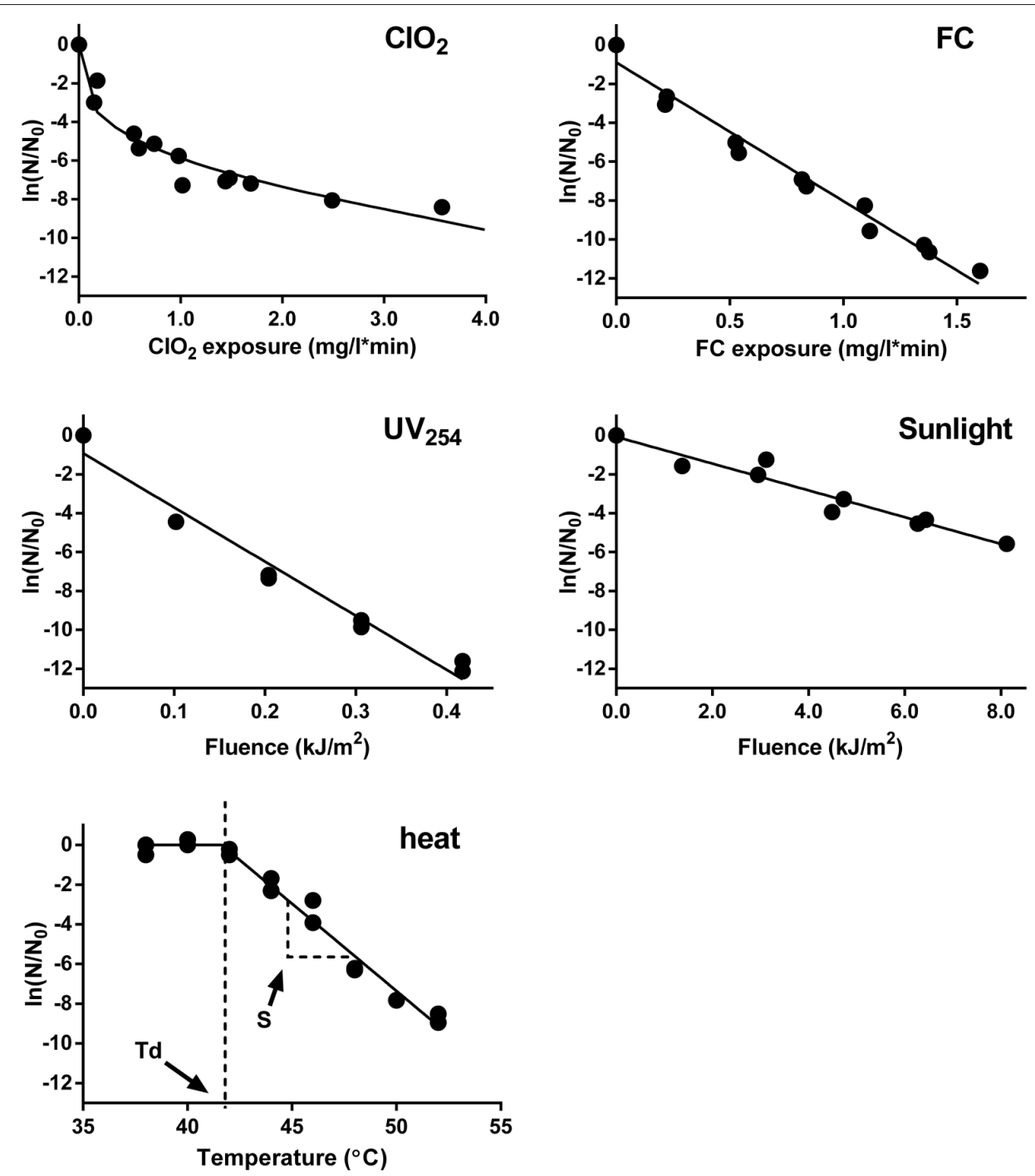

FIGURE 2 | Inactivation of E11 (WT) by $\mathrm{ClO}_{2}, \mathrm{FC}, \mathrm{UV}_{254}$, sunlight, and heat. Infectivity loss (In $\left(\mathrm{N} / \mathrm{N}_{0}\right)$ ) is plotted against disinfectant exposure for $\mathrm{ClO}_{2}$ and $\mathrm{FC}$ exposure, fluence dose for $\mathrm{UV}_{254}$ and sunlight, and temperature for heat inactivation. Experimental data was fitted using the modified $\mathrm{Hom}$ model $\left(\mathrm{ClO}_{2}\right)$,

Chick-Watson model (FC, $\mathrm{UV}_{254}$ and sunlight), and segmental linear regression (heat). Model fits are shown as solid lines. Results from duplicate experiments are presented.

was achieved within four temperature shifts during which the temperature increased to $50^{\circ} \mathrm{C}$.

\section{Cross-Resistance of $\mathrm{ClO}_{2}-$ and $\mathrm{UV}_{254}$-Tolerant Populations to Other Disinfectants}

The susceptibilities of the $\mathrm{ClO}_{2}$ - and $\mathrm{UV}_{254}$-tolerant $\mathrm{E} 11$ populations, as well as their corresponding wild-type were tested for the five inactivating treatments considered. Figure 3 shows the extent of resistance to the original stressor $\left(\mathrm{ClO}_{2}\right.$ for $\mathrm{E}_{-} \mathrm{ClO}_{2}$ and $\mathrm{UV}_{254}$ for E_UV), along with the extent of cross-resistance to each additional treatment considered. The data are presented as the inactivation rate constants of the $\mathrm{E}_{-} \mathrm{ClO}_{2}$ and E_UV populations relative to their respective wild-types, such that a value below unity indicates greater resistance than the wildtype. The absolute inactivation rate constants are reported in Supplementary Tables 1-4. For heat inactivation, the difference in decay temperature to the corresponding wild-type is shown, with the original decay temperatures reported in Supplementary Table 5 .

E_ $\mathrm{ClO}_{2}$ exhibited a $43 \%$ reduction in $k_{\mathrm{ClO} 2}$ compared to its wild-type ( $p<0.0001$; Figure 3A). $\mathrm{E}_{-} \mathrm{ClO}_{2}$ was furthermore cross-resistant to $\mathrm{FC}$, with a $19 \%$ reduction in $k_{F C}$ compared to its wild-type $(p<0.0001)$. Compared to $\mathrm{ClO}_{2}$, resistance to $\mathrm{FC}$ was thus less pronounced. Finally, no significant resistance was observed toward $\mathrm{UV}_{254}$, sunlight or heat.

E_UV exhibited resistance to $\mathrm{UV}_{254}$ inactivation, though its extent was low. Specifically, the reduction in $k_{U V}$ compared to its wild-type was $15 \%$ ( $p=0.0008$; Figure $3 B$ ). In addition, E_UV 

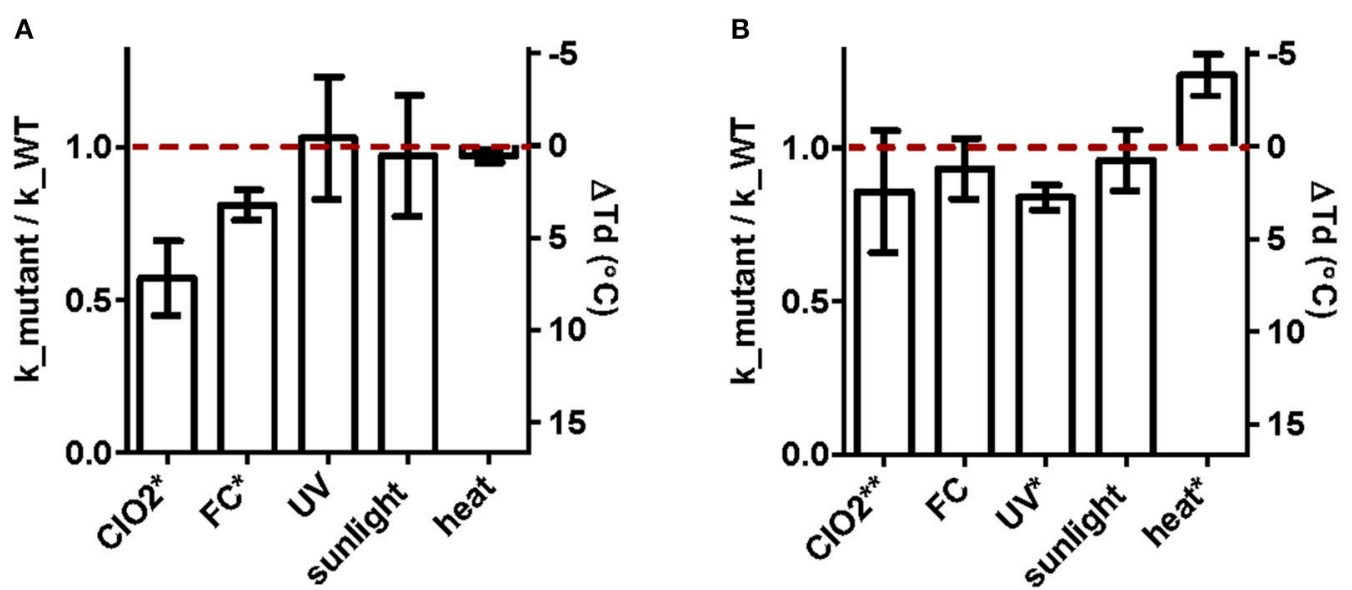

FIGURE 3 | Extent of (cross-) resistance of $\mathrm{ClO}_{2}$-resistant populations $\mathrm{E}_{-} \mathrm{ClO}_{2}$ (A) and $\mathrm{UV}_{254}$-resistant E_UV (B) upon inactivation by $\mathrm{ClO}_{2}$, $\mathrm{FC}$, UV 254 , sunlight, and heat. Except heat, results are presented as the ratio of the inactivation rate constants of the resistant populations to those of the corresponding wild-types (left $y$-axis). Cross-resistance to heat was determined from the differences in the decay temperature ( $\Delta \mathrm{Td}$ ) between the resistant populations and their wild-type (right $\mathrm{y}$-axis). The red dashed line indicates unity. Bars extending above the red line correspond to reduced resistance, and bars below indicate enhanced resistance compared to the wild-type. Asterisks indicates significant difference in resistance compared to the wild-type at the $95 \%\left({ }^{\star}\right)$ or $90 \%\left({ }^{* \star}\right)$ confidence level. Error bars represent the propagated standard errors from the model fits to pooled duplicate or triplicate experiments.

exhibited a $14 \%$ reduction in susceptibility to $\mathrm{ClO}_{2}$ compared to the wild type, though the difference was not significant at the $95 \%$ confidence level ( $p=0.0977)$. Finally, this population was more susceptible than its wild-type to heat, yielding a $4^{\circ}$ decrease in $T d$ $(p=0.0070)$, whereas no measurable resistance to FC or sunlight was observed.

\section{Viral Functions Inhibited by Different Disinfectants}

Effect of Inactivating Treatments on Genome Integrity Genome replication by the host cell could not be quantified as an isolated process, as it is preceded by host binding and internalization. We instead determined how the different inactivating treatments affect the ability of the E11 genome to be amplified by PCR. Specifically, the reduction in the qRT-PCR signal upon exposure to $\mathrm{ClO}_{2}, \mathrm{FC}$, heat, $\mathrm{UV}_{254}$, and sunlight was determined for different genome segments (Supplementary Figure 2), and was used to estimate the loss in PCR-replicability of the entire genome ( $G / G_{0}$, equation 10$)$ of E11 (WT) (Figure 4A).

As is evident from Figure $\mathbf{4 A}$, heat did not cause a measurable loss in PCR-replicable genomes. In contrast, exposure to $\mathrm{UV}_{254}$ caused a rapid decrease in $G / G_{0}$ and the rate of this decrease corresponded to that of the corresponding decrease in infectivity (Figure 4B). For sunlight-, FC-, $\mathrm{ClO}_{2}$ - inactivated viruses, the loss in PCR-replicable genome exceeded infectivity loss. Sunlight exposure caused $G / G_{0}$ to decrease by $7.4 \pm 0.8 \log _{10}$ for a 2.3 $\pm 0.54 \log _{10}$ of infectivity loss. For FC, the decrease in $G / G_{0}$ was $35 \pm 11 \log _{10}$, compared to an infectivity loss of roughly $5 \log _{10}$. Finally, for $\mathrm{ClO}_{2}$, the loss in genome replicability was further investigated at different levels of inactivation (Figure 5). Interestingly, $\log G / G_{0}$ roughly corresponded to extent of inactivation $\left(\log N / N_{0}\right)$ at low $\mathrm{ClO}_{2}$ exposures, but increasingly exceeded inactivation with increasing $\mathrm{ClO}_{2}$ exposure. Ultimately, a $5 \log _{10}$ inactivation of E11 infectivity by $\mathrm{ClO}_{2}$ resulted in a reduction of $\log G / G_{0}$ of $14.1 \pm 1.0 \log _{10}$.

These data indicate that PCR is more sensitive to genome damage induced by chemical oxidants or sunlight than the host cell. This may be rationalized by considering that the enzymes used in PCR are selected to have a low error tolerance. In BGMK cells, in contrast, only a fraction of the genome damage incurred led to inhibition of genome replication and hence inactivation. Alternatively, genome damage could also be rescued by genome recombination in the cells (Mattle and Kohn, 2012). The extent by which PCR and BGMK cells differ in their ability to replicate damaged genomes disinfectants is currently not well-understood. Despite this limitation of the assay, the PCR results are consistent with a contribution of genome damage, and a resulting loss in the replication function, to inactivation by $\mathrm{UV}_{254}, \mathrm{FC}, \mathrm{ClO}_{2}$, and sunlight.

\section{Effect of Inactivating Treatments on Host Binding}

The effect of inactivation on the ability of E11 to bind to BGMK cells was first cursorily screened by flow cytometry. Hereby we determined how inactivation affected the load of viruses bound to BGMK cells. Results revealed that the different disinfection methods affect host binding to varying extents (Figure 4C and Supplementary Figure 1). After roughly $5 \log _{10}$ of infectivity loss by $\mathrm{ClO}_{2}$ or heat, no cells carrying viruses could be detected, indicating a strong inhibition of host binding by these two treatments. A small fraction of cells with bound viruses was observed after treatment by FC, though this fraction was below the instrumental limit of quantification. Finally, host binding was only minimally affected by $\mathrm{UV}_{254}$ disinfection, resulting in negligible reduction in the observation of cells with bound viruses after treatment. 

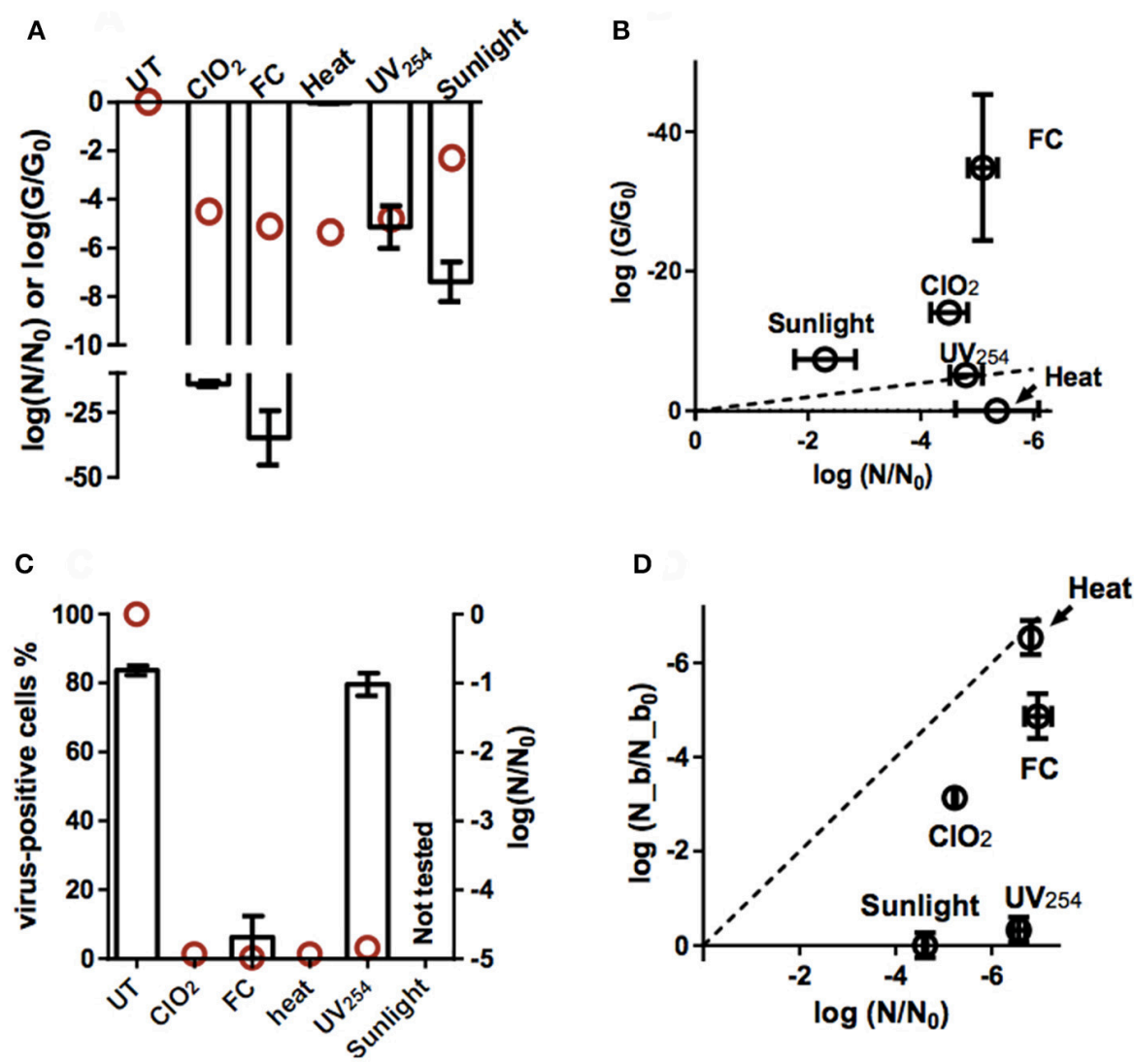

FIGURE 4 | Effect of inactivation by $\mathrm{ClO}_{2}$, FC, heat, $\mathrm{UV}_{254}$, and sunlight on viral functions. (A) Loss of PCR-replicable genome upon inactivation (log(G/G)); bars). Red circles indicate the corresponding loss in inactivation $\left(\log \left(N / N_{0}\right)\right)$. Errors bars represent the standard deviations associated with $G / G_{0}(K u, 1966)$. (B) Loss of PCR-replicable genome, plotted against infectivity loss. The dashed line represents the 1:1 correlation between genome loss and infectivity loss. Errors bars represent the the MPN enumeration error (horizontal) or standard deviations associated with $G / G_{0}$ (vertical). (C) Percentage of cells with bound viruses, determined by flow cytometry (bars, left y-axis, UT: untreated E11 sample). Red circles indicate the corresponding virus infectivity loss (right y-axis). (D) Residual fraction of bound viruses $\left(\log \left(N \_b / N \_b_{0}\right)\right)$ measured by PCR and plotted against infectivity loss. The dashed line represents the $1: 1$ correlation between binding loss and infectivity loss. Error bars represent the MPN enumeration error (horizontal) or range of duplicate experiments (vertical).

These findings were further refined by directly quantifying the concentration of viruses bound to cells (Figure 4D) by qRTPCR. The loss of binding capacity due to heat $\left(6.54 \pm 0.36 \log _{10}\right)$ corresponded to the observed infectivity loss $\left(6.81 \pm 0.02 \log _{10}\right)$. In contrast, for $\mathrm{FC}$ and $\mathrm{ClO}_{2}$, the loss in binding was smaller than infectivity loss $\left(4.87 \pm 0.48\right.$ vs. $7.0 \pm 0.28 \log _{10}$ for FC; $3.14 \pm$ 0.10 vs. $5.23 \pm 0.03 \log _{10}$ for $\mathrm{ClO}_{2}$ ). Finally, $\mathrm{UV}_{254}$ and sunlight manifested less than half a log of binding loss for an infectivity loss was $6.56 \pm 0.14 \log _{10}$ and $4.61 \pm 0.03 \log _{10}$ respectively.

Assuming a first-order rate of loss in host binding (Wigginton et al., 2012; Zhong et al., 2017), and given the approximate firstorder inactivation over the range of disinfection exposures considered, the contribution of binding loss to overall inactivation can be estimated from a log-log plot of binding loss vs. infectivity loss. In Figure 4D, the dotted 1:1 line indicates the region where binding loss can account for all the infectivity loss. The region below the line signifies that binding loss is smaller than infectivity loss, such that other viral functions must also be affected by a given disinfectant. Figure 4D reveals that for heat, binding loss fully accounts for inactivation, whereas for $\mathrm{FC}$ and $\mathrm{ClO}_{2}$, the contribution to inactivation is $\sim 70$ and $60 \%$ respectively. Finally, for $\mathrm{UV}_{254}$ and sunlight, host binding remains unaffected. Note, however, that the extent of residual binding may be overestimated for most treatments, as it was not possible to control for non-specific binding of inactivated viruses. The only exception is heat, where binding loss was proportional to infectivity loss, such that non-specific binding was unlikely.

\section{Comparison of the Mutation Spectrum of the Resistant Populations}

Disinfection resistance arises from mutations to the viral genome which confer an advantage with respect to withstanding disinfection. A comparison of the mutations fixed in each of the resistant populations, along with their likely effects on the viral phenotype, may further aid in understanding the occurrence or absence of cross-resistance.

A total of 12 non-synonymous mutations were identified (Table 1). Of these, five were shared by both resistant populations, and may be a result of adaptation to cell culturing. 


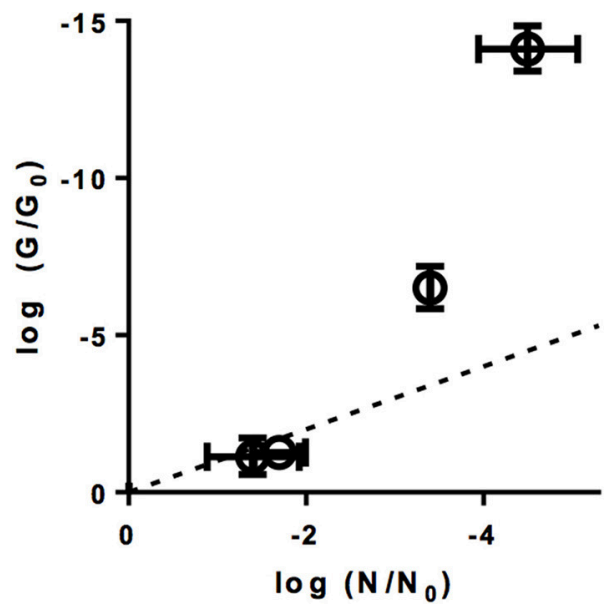

FIGURE 5 | Genome loss $\log \left(G / G_{0}\right)$ at different levels of inactivation $\log \left(N / N_{0}\right)$ by $\mathrm{ClO}_{2}$. The dotted line represents the 1:1 correlation between inactivation and genome loss. Errors bars represent the MPN enumeration error (horizontal) or the standard deviation associated with $G / G_{0}$ (vertical) (Ku, 1966).

E_ $\mathrm{ClO}_{2}$ furthermore exhibited unique non-synonymous mutations in the structural protein VP1, whereas unique non-synonymous mutations in E_UV were located in the replication-related proteins $2 \mathrm{C}$ and $3 \mathrm{D}$, as well as in structural protein VP4. Given that there was no cross-resistance of $\mathrm{E}_{-} \mathrm{ClO}_{2}$ to $\mathrm{UV}_{254}$ (Figure $\mathbf{3 A}$ ) and only minor cross-resistance of E_UV to $\mathrm{ClO}_{2}$, these unique mutations serve as candidate mutations responsible for the resistance of E_UV to $\mathrm{UV}_{254}$ and of $\mathrm{E}_{-} \mathrm{ClO}_{2}$ to $\mathrm{ClO}_{2}$ respectively.

\section{DISCUSSION}

The occurrence of viral multi-resistance to disinfectants with different modes of action appears limited in the virus populations tested herein. Among the 10 combinations of resistances and disinfectants tested, only one significant cross-resistance was observed between two chemical oxidants, resulting in a reduced sensitivity of $\mathrm{ClO}_{2}$-resistant virus to free chlorine. To rationalize the cross-resistance patterns observed, we investigated the mechanisms of action of each disinfectant. Hereby we hypothesized that cross-resistance was a result of a shared mechanism of action of two disinfectants, whereas the absence of cross-resistance is found among treatments acting by different mechanisms. As discussed above, most studies to date report genome damage and inhibition of host binding as the main action of most disinfectants. We therefore focused our mechanistic investigation on these two traits.

\section{Mechanisms of E11 Inactivation}

Based on our findings of reduction in genome integrity (Figures 4A,B) and inhibition of host binding (Figures 4C,D), an overview of the main mechanisms of inactivation is presented in Figure 6. Roughly, the modes of action of the different disinfectants can be categorized into three groups, depending on the major viral function impaired. First, for heat, inactivation can be attributed entirely to a loss in host binding. Accordingly, no other viral functions are implicated in inactivation and all genomes remain as replicable as in the untreated samples. Second, for $\mathrm{UV}_{254}$ and sunlight, no or minimal binding loss was detected. Inactivation must thus be due to losses in other viral functions, such as genome internalization, replication or virion assembly. While these functions were not tested individually, both $\mathrm{UV}_{254}$ and sunlight resulted in a considerable decrease in the fraction of PCR-replicable genome copies. The extensive genome degradation observed by PCR supports the conclusion that the main mechanism of inactivation by both $\mathrm{UV}_{254}$ and sunlight involves genome damage, and hence inhibition of replication. Third, inactivation by the oxidants $\mathrm{ClO}_{2}$ and $\mathrm{FC}$ cannot be attributed to loss in a single virus function. Their mode of action mainly involves a reduction in host binding, yet losses in other functions also contribute significantly. As observed for $\mathrm{UV}_{254}$ and sunlight, treatment by $\mathrm{FC}$ and $\mathrm{ClO}_{2}$ also leads to extensive genome degradation, which likely causes a loss of genome replication.

The proposed mechanisms agree with previous studies on enterovirus that demonstrated that heat and FC inhibited host binding of poliovirus (Nuanualsuwan and Cliver, 2003a) and that $\mathrm{UV}_{254}$ 's primary target is the genome (Helentjaris and Ehrenfeld, 1977; Nuanualsuwan and Cliver, 2003b). The proposed mechanisms of inactivation of E11 are also are largely consistent with those previously described for MS2 (Wigginton et al., 2012). Major discrepancies were only found for $\mathrm{ClO}_{2}$ : this disinfectant was previously reported to have no effect on the genome integrity of MS2 (Wigginton et al., 2012), and no effect on host binding for poliovirus (Alvarez and O'Brien, 1982), whereas both these functions were inhibited in E11. The disagreement may be linked to differences in the viral species investigated and their binding motifs, as well as to the disinfectant exposures and solution conditions considered. Furthermore, the inactivation curve of $\mathrm{E} 11$ by $\mathrm{ClO}_{2}$ exhibits a pronounced tail (Figure 2A). This feature has previously been reported for virus inactivation by $\mathrm{ClO}_{2}$, and has been attributed to multiple causes, including the presence of resistant subpopulations or the gradual accumulation of protein oxidation products that form a protective layer on the viral capsid (Berman and Hoff, 1984; Chen and Vaughn, 1990; Thurston-Enriquez et al., 2005; Lim et al., 2010; Jin et al., 2013; Sigstam et al., 2013). The tailing inactivation curve may cause the extent of genome damage by $\mathrm{ClO}_{2}$ to not scale linearly with inactivation, but instead to increasingly exceed the extent of inactivation (Figure 5). As such, it is likely that the relative contribution of genome damage to inactivation by $\mathrm{ClO}_{2}$ depends on the $\mathrm{ClO}_{2}$ exposure and the extent of inactivation considered.

\section{Cross-Resistance of E11 to Different Disinfectants Is Specific to the Mechanism of Inactivation}

In the $\mathrm{ClO}_{2}$-resistant population $\mathrm{E}_{-} \mathrm{ClO}_{2}$, we previously identified that resistance was rooted in the ability to utilize an additional host receptor, which was in turn linked to mutations 
in VP1 (Zhong et al., 2017). This trait allowed the resistant population to better maintain host binding in the presence of $\mathrm{ClO}_{2}$, and hence to tolerate higher $\mathrm{ClO}_{2}$ exposure. Crossresistance of $\mathrm{E}_{-} \mathrm{ClO}_{2}$ may thus be expected to any disinfectant that inhibits host binding (Figure 6). Consistent with this hypothesis, $\mathrm{E}_{-} \mathrm{ClO}_{2}$ also exhibited resistance to FC. In contrast, no cross-resistance to heat was observed, even though this treatment also affects host binding. This result can be rationalized by considering that $\mathrm{ClO}_{2}$ and $\mathrm{FC}$ both oxidize viral proteins, whereas heat acts by denaturation (Rombaut et al., 1994; Dodd, 2012). While the mutations in $\mathrm{E}_{-} \mathrm{ClO}_{2}$ protected the virus from oxidation by allowing alternative receptor use, and by replacing oxidation-reactive by stable amino acids (Table 1) (Sharma and Sohn, 2012), they may not yield the same benefits for protection from denaturation. Finally, the absence of cross-resistance to $\mathrm{UV}_{254}$ and sunlight, which do not act on host binding, supports that resistance to $\mathrm{ClO}_{2}$ is a mechanism-specific trait.

In population E_UV, resistance to $\mathrm{UV}_{254}$ implies a greater ability of the resistant population to deal with mutations accumulated through the action of $\mathrm{UV}_{254}$. This ability should also extend to sunlight, since solar UVB $(280-315 \mathrm{~nm})$ is also known to have mutagenic action (Pfeifer et al., 2005). Yet, population E_UV did not demonstrate measurable crossresistance to sunlight. This observation can be explained by considering that the $\mathrm{UV}_{254}$-resistance of this population was relatively mild, and that $\mathrm{UV}$ at different wavelengths have distinct mutational specificity (Pfeifer et al., 2005).

No cross-resistance of E_UV was observed for heat, which is consistent with its mode of action being entirely protein dependent. Instead, E_UV exhibited enhanced susceptibility to heat. We tentatively attribute this feature to mutation Y33F, which was only found in E_UV, and which is located on the Nterminus of structural protein VP4. The intertwining N-terminus extension of VP1, VP3, and VP4 form a network of proteinprotein interactions on the interior of the capsid that is crucial

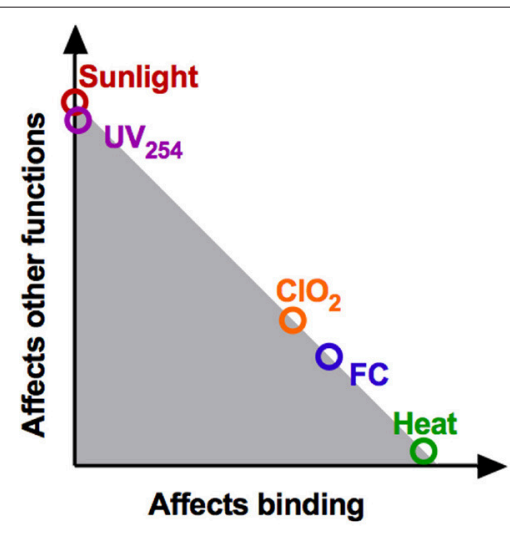

FIGURE 6 | Schematic summary of the contributions of binding loss and other viral functions to overall inactivation. This location of the data points correspond to the ratio of $\log \left(N \_b / N \_b_{0}\right): \log \left(N / N_{0}\right)$ (see Figure 4D). The shaded region represents the additive effects of loss of binding, genome replication and potentially other functionalities. to viral stability (Knipe and Howley, 2007). Therefore, we argue that Y33F on VP4 rendered the E_UV less structurally stable and hence more heat-sensitive. This proposition is supported by the prediction of protein stability changes upon single point mutations using I-Mutant2.0 (Capriotti et al., 2005, 2008). Mutation $\mathrm{Y33F}$ was estimated to yield a Gibbs free energy change of -0.76 at $45^{\circ} \mathrm{C}$ compared to the wild-type. Therefore, Y33F is destabilizing the protein. I-Mutant, however, considers only single proteins, hence free energy calculations that take into consideration inter-protein interactions are needed to validate the result.

Finally, E_UV was slightly cross-resistant to $\mathrm{ClO}_{2}$, even though these two disinfectants act by drastically different mechanisms. This finding indicates that populations with a more general resistance spectrum can exist. However, the inverse crossresistance was not found: $\mathrm{E}_{-} \mathrm{ClO}_{2}$ remained susceptible to $\mathrm{UV}_{254}$. This supports the notion that the multi-resistance of E_UV is not linked to the resistance to $\mathrm{UV}_{254}$ per se, but may be induced by the experimental evolution assay used to produce the evolved populations. Specifically, resistant populations were produced by repeated and drastic reduction of their population numbers by either $\mathrm{ClO}_{2}$ or $\mathrm{UV}_{254}$ exposure, followed by regrowth. This action likely selected for those variants that most efficiently proliferated under the experimental conditions used. Efficient proliferation may be aided by enhanced host binding, which in turn is also beneficial to resistance to $\mathrm{ClO}_{2}$. Interestingly, both evolved populations shared mutations that are confirmed or probable sites associated with a host receptor switch (VP2G139R, VP1-M238V, and VP1-K259E; Table 1) (Zhong et al., 2017). This supports the notion that analogous to $\mathrm{E}_{-} \mathrm{ClO}_{2}$, the $\mathrm{ClO}_{2}$ resistance manifested in $\mathrm{E} \_\mathrm{UV}$ is also associated with a better use of an alternative cell receptor.

Given the significant cross-resistance of $\mathrm{ClO}_{2}$ and $\mathrm{FC}$ observed in E_ $\mathrm{ClO}_{2}$, the presence of cross-resistance of E_UV to $\mathrm{ClO}_{2}$ but absence of cross-resistance to $\mathrm{FC}$ is surprising. However, resistance of $\mathrm{E}_{-} \mathrm{ClO}_{2}$ to $\mathrm{FC}$ is less pronounced compared to $\mathrm{ClO}_{2}$ (Figure 3A), and cross-resistance to $\mathrm{ClO}_{2}$ in E_UV was only slight (Figure 3B). Combined, these two factors likely rendered any cross-resistance of E_UV to FC too small to be experimentally measured.

Overall, this study supports the hypothesis that crossresistance is mainly found among disinfectants that act by a similar mechanism. To confirm this result, future studies should include viruses with resistance to less specific stressors, such as ozone or free chlorine, which significantly target both viral proteins and genomes. It is conceivable that viruses evolved under pressure of such non-selective disinfectants evolve more general resistances that extend to both genome- and proteinactive disinfectants.

\section{Implications for Virus Control}

As discussed in the introduction, the presence of disinfectionresistant viruses in the environment and is already wellestablished, though the origin of their resistance is not always known. A potential new source of resistant viruses may be the increasing practice of direct potable reuse of wastewater. In these systems, waterborne viruses may remain in the 
"treatment-consumption-excretion-treatment" cycle, where they can become subjected to iterate disinfectant exposures and cause new infections. In such a setting, we should be conscious of the potential emergence of disinfection-resistant viruses, and evaluate the best approaches to control their occurrence.

Our results to date suggest that viruses with resistance to a given disinfectant can be controlled by a disinfectant with a different mode of action. This may be achieved by implementing a double disinfection barrier that uses different disinfectants in sequence. From our study on echovirus, a smart choice of disinfectant to include in a double barrier setup is $\mathrm{UV}_{254}$. First, $\mathrm{UV}_{254}$ is a rather non-selective disinfectant that acts on all genetic material to a roughly similar extent (Lytle and Sagripanti, 2005). This is a stark contrast to a disinfectant like $\mathrm{ClO}_{2}$, which only efficiently targets specific amino acids, namely cysteine, tyrosine, tryptophan, histidine, and proline (Tan et al., 1987; Sharma and Sohn, 2012). Compared to $\mathrm{ClO}_{2}$, it is thus unlikely that any virus will ever fully escape the pressure of $U_{254}$. Second, the resistance to $\mathrm{UV}_{254}$ was slight compared to that to $\mathrm{ClO}_{2}$ (though we cannot exclude that different experimental approaches to produce the resistant virus result in greater resistance). Even if the resistance is minor, however, it remains necessary to include an additional disinfection step using a different disinfectant, such as free chlorine, to control $\mathrm{UV}_{254}$-resistant organisms.

The efficiency of different double disinfection barriers to control resistant viruses remains to be tested in future work. In particular, this approach should be validated for additional

\section{REFERENCES}

Alvarez, M. E., and O’Brien, R. T. (1982). Mechanisms of inactivation of poliovirus by chlorine dioxide and iodine. Appl. Environ. Microbiol. 44, 1064-1071.

Ballester, N. A., and Malley, J. P. (2004). Sequential disinfection of adenovirus type 2 with UV-chlorine-chloramine. J. Am. Water Work Assoc. 2, 97-103.

Bates, R. C., Shaffer, P. T., and Sutherland, S. M. (1977). Development of poliovirus having increased resistance to chlorine inactivation. Appl. Environ. Microbiol. 34, 849-853.

Berman, D., and Hoff, J. C. (1984). Inactivation of simian rotavirus sal1 by chlorine, chlorine dioxide, and monochloramine. Appl. Environ. Microbiol. 48, 317-323.

Bosshard, F., Armand, F., Hamelin, R., and Kohn, T. (2013). Mechanisms of human adenovirus inactivation by sunlight and UVC light as examined by quantitative PCR and quantitative proteomics. Appl. Environ. Microbiol. 79, 1325-1332. doi: 10.1128/AEM.03457-12

Capriotti, E., Fariselli, P., and Casadio, R. (2005). I-Mutant2.0: predicting stability changes upon mutation from the protein sequence or structure. Nucleic Acids Res. 33, W306-W310. doi: 10.1093/nar/gki375

Capriotti, E., Fariselli, P., Rossi, I., and Casadio, R. (2008). A three-state prediction of single point mutations on protein stability changes. BMC Bioinformatics 9(Suppl. 2):S6. doi: 10.1186/1471-2105-9-S2-S6

Chen, Y. S., and Vaughn, J. M. (1990). Inactivation of human and simian rotaviruses by chlorine dioxide. Appl. Environ. Microbiol. 56, 1363-1366.

Crotty, S., Maag, D., Arnold, J. J., Zhong, W., Lau, J. Y., Hong, Z., et al. (2000). The broad-spectrum antiviral ribonucleoside ribavirin is an RNA virus mutagen. Nat. Med. 6, 1375-1379. doi: 10.1038/82191

David, F. P. A., Delafontaine, J., Carat, S., Ross, F. J., Lefebvre, G., Jarosz, Y., et al. (2014). HTSstation: a web application and open-access libraries for high-throughput sequencing data analysis. PLOS ONE 9:e85879. doi: 10.1371/journal.pone.0085879 viruses, as their inactivation mechanisms by the disinfectants tested may differ from that of E11. Furthermore, research should identify ideal combinations of disinfectants and optimal treatment regimes. Ultimately, such a setup should be able to successfully inactivate resistant viruses while avoiding the emergence of multi-resistant viruses.

\section{AUTHOR CONTRIBUTIONS}

QZ and TK designed the experimental plan. QZ, AC, VB, and RO conducted the experiments. QZ, TK, and RO analyzed the data. $\mathrm{QZ}, \mathrm{AC}$, and TK wrote the manuscript.

\section{FUNDING}

This work was funded by the Swiss National Foundation (project numbers 31003A_138319 and 31003A_163270).

\section{SUPPLEMENTARY MATERIAL}

The Supplementary Material for this article can be found online at: http://journal.frontiersin.org/article/10.3389/fmicb. 2017.01928/full\#supplementary-material

Additional details on the qRT-PCR protocol, figures on analysis of flow cytometer output, reduction of PCR replicable genome segments and absolute inactivation rate constants.

Dodd, M. C. (2012). Potential impacts of disinfection processes on elimination and deactivation of antibiotic resistance genes during water and wastewater treatment. J. Environ. Monit. 14, 1754-1771. doi: 10.1039/c2em00006g

Fletcher, I. J., and Hemmings, P. (1985). Determination of chlorine dioxide in potable waters using chlorophenol red. Analyst 110, 695-699. doi: 10.1039/an9851000695

Fong, T.-T., and Lipp, E. K. (2005). Enteric viruses of humans and animals in aquatic environments: health risks, detection, and potential water quality assessment tools. Microbiol. Mol. Biol. Rev. 69, 357-371. doi: 10.1128/MMBR. 69.2 .357

Ford, T. E. (1999). Microbiological safety of drinking water: United States and global perspectives. Environ. Health Perspect. 107, 191-206. doi: $10.2307 / 3434483$

Haas, C. N., and Joffe, J. (1994). Disinfection under dynamic conditions: modification of Hom's model for decay. Environ. Sci. Technol. 28, 1367-1369. doi: 10.1021/es00056a028

Haas, C. N., Rose, J. B., and Gerba, C. P. (2014). Quantitative Microbial Risk Assessment, 2nd Edn. Hoboken, NJ: John Wiley and Sons, Inc.

Helentjaris, T., and Ehrenfeld, E. (1977). Inhibition of host cell protein synthesis by UV-inactivated poliovirus. J. Virol. 21, 259-267.

Jin, M., Shan, J., Chen, Z., Guo, X., Shen, Z., Qiu, Z., et al. (2013). Chlorine dioxide inactivation of enterovirus 71 in water and its impact on genomic targets. Environ. Sci. Technol. 47, 4590-4597. doi: 10.1021/es305282g

Jin, M., Zhao, Z.-G., Wang, X.-W., Shen, Z.-Q., Xu, L., Yu, Y.-M., et al. (2012). The 40-80 nt region in the 5-NCR of genome is a critical target for inactivating poliovirus by chlorine dioxide. J. Med. Virol. 84, 526-535. doi: 10.1002/jmv. 23221

Knipe, D. M., and Howley, P. M. (Eds) (2007). Fields Virology, 5th Edn. Philadelphia, PA: Lippincott Williams \& Wilkins.

Ku, H. H. (1966). Notes on the use of propagation of error formulas. J. Res. Natl. Bur. Stand. Sect. C Eng. Instrum. 70C, 263-273. doi: 10.6028/jres.070C.025 
Li, J. W., Xin, Z. T., Wang, X. W., Zheng, J. L., and Chao, F. H. (2004). Mechanisms of inactivation of hepatitis A virus in water by chlorine dioxide. Water Res. 38, 1514-1519. doi: 10.1016/j.watres.2003.12.021

Lim, M. Y., Kim, J.-M., and Ko, G. (2010). Disinfection kinetics of murine norovirus using chlorine and chlorine dioxide. Water Res. 44, 3243-3251. doi: 10.1016/j.watres.2010.03.003

Lytle, C. D., and Sagripanti, J.-L. (2005). Predicted inactivation of viruses of relevance to biodefense by solar radiation. J. Virol. 79, 14244-14252. doi: 10. 1128/JVI.79.22.14244-14252.2005

Maillard, J.-Y., Hann, A. C., and Perrin, R. (1998). Resistance of Pseudomonas aeruginosa PAO1 phage F116 to sodium hypochlorite. J. Appl. Microbiol. 85, 799-806. doi: 10.1046/j.1365-2672.1998.00578.x

Mattle, M. J., and Kohn, T. (2012). Inactivation and tailing during UV254 disinfection of viruses: contributions of viral aggregation, light shielding within viral aggregates, and recombination. Environ. Sci. Technol. 46, 10022-10030. doi: $10.1021 /$ es302058v

Nuanualsuwan, S., and Cliver, D. O. (2003a). Capsid functions of inactivated human picornaviruses and feline calicivirus. Appl. Environ. Microbiol. 69, 350-357. doi: 10.1128/AEM.69.1.350

Nuanualsuwan, S., and Cliver, D. O. (2003b). Infectivity of RNA from inactivated poliovirus. Appl. Environ. Microbiol. 69, 1629-1632. doi: 10.1128/AEM.69.3.1629

Olivieri, V. P., Hauchman, F. S., Noss, C. I., and Vasl, R. (1985). "Mode of action of chlorine dioxide on selected viruses," in Water Chlorination Chemistry: Environmental Impact and Health Effects, Vol 5, ed R. L. Jolley (Chelsea, MI: Lewis Publishers), 619-634.

Payment, P., Tremblay, M., and Trudel, M. (1985). Relative resistance to chlorine of poliovirus and coxsackievirus isolates from environmental sources and drinking water. Appl. Environ. Microbiol. 49, 981-983.

Pecson, B. M., Martin, L. V., and Kohn, T. (2009). Quantitative PCR for determining the infectivity of bacteriophage MS2 upon inactivation by heat, UV-B radiation, and singlet oxygen: advantages and limitations of an enzymatic treatment to reduce false-positive results. Appl. Environ. Microbiol. 75, 5544-5554. doi: 10.1128/AEM.00425-09

Pfeifer, G. P., You, Y., and Besaratinia, A. (2005). Mutations induced by ultraviolet light. Mutat. Res. 571, 19-31. doi: 10.1016/j.mrfmmm.2004.06.057

Rahn, R. (1997). Potassium iodide as a chemical actinometer for $254 \mathrm{~nm}$ radiation : use of iodate as an electron scavenger. Photochem. Photobiol. 66, 450-455. doi: 10.1111/j.1751-1097.1997.tb03243.x

Rice, E. W., Baird, R. B., Eaton, A. D., and Clesceri, L. S. (2012). Standard Methods for the Examination of Water and Wastewater, 22nd Edn. Washington, DC: American Public Health Association; American Water Works Association; Water Environment Federation.

Rombaut, B., Verheyden, B., Andries, K., and Boeyé, A. (1994). Thermal inactivation of oral polio vaccine: contribution of RNA and protein inactivation. J. Virol. 68, 6454-6457.

Shaffer, P. T., Metcalf, T. G., and Sproul, O. J. (1980). Chlorine resistance of poliovirus isolants recovered from drinking water. Appl. Environ. Microbiol. 40, 1115-1121.
Sharma, V. K., and Sohn, M. (2012). Reactivity of chlorine dioxide with amino acids, peptides, and proteins. Environ. Chem. Lett. 10, 255-264. doi: 10.1007/s10311-012-0355-5

Sigstam, T., Rohatschek, A., Zhong, Q., Brennecke, M., and Kohn, T. (2013). On the cause of the tailing phenomenon during virus disinfection by chlorine dioxide. Water Res. 48, 82-89. doi: 10.1016/j.watres.2013. 09.023

Simonet, J., and Gantzer, C. (2006). Degradation of the poliovirus 1 genome by chlorine dioxide. J. Appl. Microbiol. 100, 862-870. doi: 10.1111/j.1365-2672.2005.02850.x

Suess, M. J. (Ed) (1982). Biological, Bacteriological and Virological Examination: A Reference Handbook, 1st Edn. Oxford: Pergamon Press Ltd.

Tan, H. K., Wheeler, W. B., and Wei, C. I. (1987). Reaction of chlorine dioxide with amino acids and peptides: kinetics and mutagenicity studies. Mutat. Res. 188, 259-266. doi: 10.1016/0165-1218(87)90002-4

Thurston-Enriquez, J. A., Haas, C. N., Jacangelo, J., and Gerba, C. P. (2005). Inactivation of enteric adenovirus and feline calicivirus by chlorine dioxide. Appl. Environ. Microbiol. 71, 3100-3105. doi: 10.1128/AEM.71. 6.3100

Triantafilou, M., Wilson, K. M., and Triantafilou, K. (2001). Identification of echovirus 1 and coxsackievirus A9 receptor molecules via a novel flow cytometric quantification method. Cytometry 43, 279-289. doi: 10.1002/1097-0320(20010401)43:4<279::AID-CYTO1060>3.0.CO;2-B

USEPA (2016). Drinking water contaminant candidate list 4-final. Fed. Regist. 81, $81099-81114$.

Wigginton, K. R., Pecson, B. M., Sigstam, T., Bosshard, F., and Kohn, T. (2012). Virus inactivation mechanisms: impact of disinfectants on virus function and structural integrity. Environ. Sci. Technol. 46, 12069-12078. doi: 10.1021/es3029473

Zhong, Q., Carratalà, A., Nazarov, S., Guerrero-Ferreira, R. C., Piccinini, L., Bachmann, V., et al. (2016). Genetic, structural, and phenotypic properties of MS2 coliphage with resistance to $\mathrm{ClO} 2$ disinfection. Environ. Sci. Technol. 50, 13520-13528. doi: 10.1021/acs.est.6b04170

Zhong, Q., Carratalà, A., Shim, H., Bachmann, V., Jensen, J. D., and Kohn, T. (2017). Resistance of echovirus 11 to $\mathrm{ClO} 2$ is associated with enhanced host receptor use, altered entry routes and high fitness. Environ. Sci. Technol. 51, 10746-10755. doi: 10.1021/acs.est.7b03288

Conflict of Interest Statement: The authors declare that the research was conducted in the absence of any commercial or financial relationships that could be construed as a potential conflict of interest.

Copyright ( $\odot 2017$ Zhong, Carratalà, Ossola, Bachmann and Kohn. This is an openaccess article distributed under the terms of the Creative Commons Attribution License (CC BY). The use, distribution or reproduction in other forums is permitted, provided the original author(s) or licensor are credited and that the original publication in this journal is cited, in accordance with accepted academic practice. No use, distribution or reproduction is permitted which does not comply with these terms. 